Volatility of Thorium Active Deposit

This content has been downloaded from IOPscience. Please scroll down to see the full text. 1913 Proc. Phys. Soc. London 26248

(http://iopscience.iop.org/1478-7814/26/1/326)

View the table of contents for this issue, or go to the journal homepage for more

Download details:

IP Address: 131.91.169.193

This content was downloaded on 06/09/2015 at $14: 42$

Please note that terms and conditions apply. 
XXVI. Volatility of Thorium Active Deposit. By T. BARRatT, A.R.C.S., B.Sc., and A. B. Wood, M.Sc.

RECEIVED APRI 21, 1914.

\section{I. -Introduction.}

Is a Paper published in 1911 by E. Marsden and one of us,* it was first proved that the two $\alpha$-ray products contained in $\mathrm{ThC}$ are not successive, but belong to different branches of the thorium series. The following scheme of disintegration was suggested :-

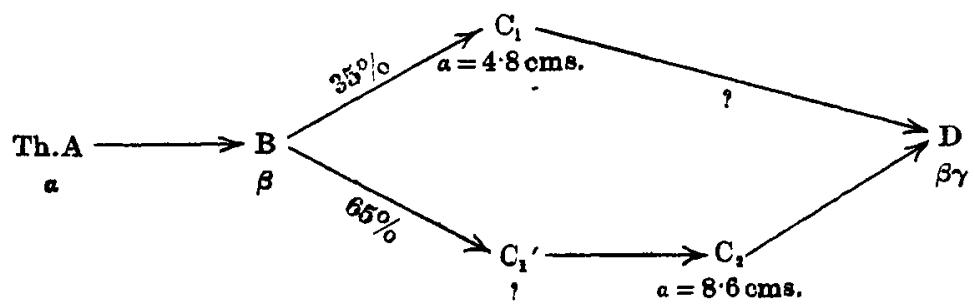

The hypothetical product $\mathrm{C}_{1}{ }^{\prime}$ was included in order to account for the fact that $C_{1}$ and $C_{2}$ appeared to be always present in the same relative proportions, viz., 35:65. This could not possibly be the case if $\mathrm{C}_{2}$ came directly from $B$, unless $C_{2}$ had the same period as $\mathrm{C}_{1}$. This, however, is unlikely, as the range of $\mathrm{C}_{2}$ is nearly double that of $\mathrm{C}_{1}$, and in the case of most other $a$-ray products of any particular radio-active family, Geiger and Nuttall's rule that $\log$ (transformation constant)/log (range) is a constant applies pretty closely. Marsden and Darwin, $\dagger$ after further experiments with thorium active deposit, proposed the scheme :-

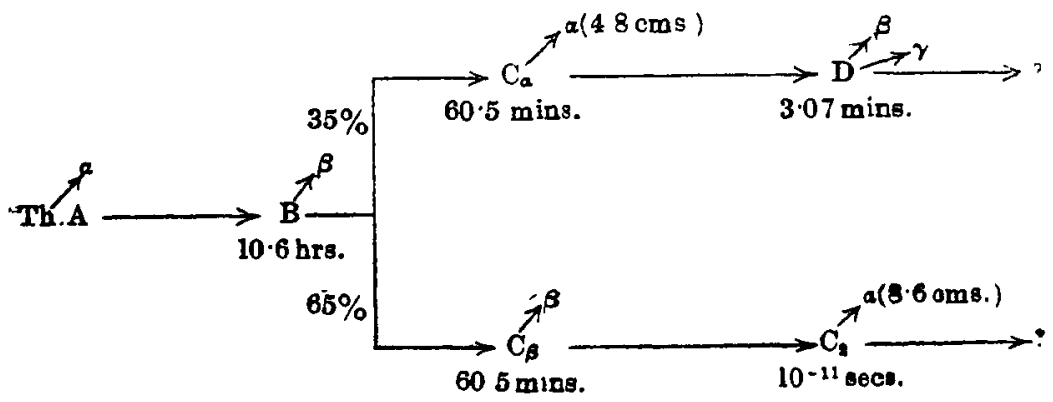

" Marsden and Barratt, " Proc." Phys. Soc., 24, p. 50, 1911.

† Marsden and Darwin," Proc." Roy. Soc., A, IXXXVII., p. 17, 1912, 
In this arrangement $\mathrm{C}_{\alpha}$ and $\mathrm{C}_{\beta}$ are supposed to represent, not two different products, but the same product breaking down in two different ways, one with the expulsion of an $\alpha$-particle, giving rise to $\mathrm{D}$, the other emitting a $\beta$-particle, and forming $\mathrm{C}_{2}$, which in its turn is transformed to an unknown substance on expelling an $\alpha$-particle.

Miss Meitner,* however, obtained results which seemed to indicate that the hypothetical substance $\mathrm{C}_{1}{ }^{\prime}$ (or $\mathrm{C}_{\beta}$ ) could be obtained tree irom $\mathrm{C}_{1}$ (or $\mathrm{C}_{a}$ ). On adding a few drops of stannous chloride to an $\mathrm{HCl}$ solution of the active deposit, and dipping successive nickel plates in the solution, the $\mathrm{C}_{\alpha}$ appeared to be removed, leaving $\mathrm{C}_{\beta}$ and $\mathrm{D}$ in solution. The latter was then boiled to dryness, divided into two portions, and, the $\mathrm{D}$ being first allowed to decay, activities measured by $\alpha$ and $\gamma$-rays respectively. The $\gamma$-curve rose from zero, showing that $\mathrm{C}_{a}$, and therefore also $\mathrm{D}$ (which produces the $\gamma$-rays), had been removed by the nickel plates. The $\alpha$-radiation, however, arising presumably from $\mathrm{C}_{2}$, did not commence trom zero, showing that $\mathrm{C}_{\beta}$ (with $\mathrm{C}_{2}$ ) had not been completely removed.

Marsden and Wilson $\uparrow$ repeated Miss Meitner's experiments, and acknowledged obtaining sometimes the same results, but concluded on the whole that they were anomalous, and due mainly to the fact that, in the presence of $\mathrm{HCl}, \mathrm{C}$ volatilises at a comparatively low temperature. In their experiments the active deposit was heated to temperatures not accurately measured, but estimated at $250^{\circ} \mathrm{C}$. to $300^{\circ} \mathrm{C}$.

In view of these conflicting results, it was thought desirable to attempt to separate the members of the active deposit by heating the latter to various accurately measured temperatures, and following the consequent changes of activity, making measurements of both $\alpha$ and $\beta$-radiations.

\section{II.-Previous Work on Volatilisation.}

The first attempt to separate the members of the thorium active deposit by volatilisation appears to have been made by Miss Gates: in 1903. She obtained apparently a partial separation of $B$ and $C$ (then known as $A$ and $B$ respectively). Two years later Miss Slater§ heated for one or two minutes a

* Lise Meitner, “Phys. Zeit.," XIII., p. 623, 1912.

† Marsden and Wilson, "Phil. Mag.," pp. 354-361, Aug., 1913.

+ Miss Gates, "Phys. Rev.," 16, p. 300, 1903.

\$ Miss Slater, " Phil. Mag.," 9, 628, 1905. 
platinum wire coated with the active deposit to temperatures up to about $1,300^{\circ} \mathrm{C}$. B commenced to volatilise at $630^{\circ} \mathrm{C}$., but no part of $\mathrm{C}$ was removed till a temperature of $730 \mathrm{deg}$. was reached. At $1,280^{\circ} \mathrm{C}$. the whole of $\mathrm{B}$ was removed, and 99 per cent. of $\mathrm{C}$, the small remaining activity (prestmably measured by $\alpha$-radiation) diminishing with a period of about one hour. The temperatures in these experiments were measured by a thermo-junction. No $\beta$-ray measurements were made, so that the results do not throw much light on the question of the separability of the various products now known to be present. in the thorium series.

\section{III.-Apparatus and Measurements.}

(a) Active Deposit Undissolved in Acid.

An electric furnace, consisting of a porcelain tube wound with strip platinum, was employed for heating the active deposit to any required temperature. The internal dimensions were, approximately, length $60 \mathrm{~cm}$., diameter $4.5 \mathrm{~cm}$., this large size ensuring that the volatilised portion of the deposit could easily escape, and would have little chance of settling once more on the plate on which it was originally deposited. The temperature was accurately measured by a platinum thermometer, contained in a tube of biscuit porcelain, in connection with a Callendar-Griffiths" "bridge," whose coils were carefully calibrated in the usual way. The "ice" and "steam" points were determined, and verified from time to time. The $\delta$-coefficient of the platinum was taken as 1.50 . In order to ensure that the temperature of the active deposit was that indicated by the thermometer, the active plate was. placed in a small flat platinum "basket," which was hung on the thermometer near its extreme end. The active deposit was obtained from a preparation of mesothorium, very kindly Tent by Mr. F. H. Glew. By a simple arrangement the active deposit could be obtained on one side only of a platinum foil, and by a suitable adjustment of the conditions of exposure considerable variations in its activity could be obtained. In earlier experiments the results were somewhat variable, owing to the fact that the platinum used was not perfectly clean. The slightest trace of grease, \&c., is enough to spoil an experiment, as the active matter is carried away when the grease evaporates. (This may possibly account for the comparatively low temperatures of volatilisation obtained by Miss. 
Slater.*) Consequently the foils were strongly heated for some time in a blow-pipe flame before being exposed to the emanation. To check results, the active plates were frequently placed in the furnace in pairs. It was also found advisable not to use an electric field when exposing the plates to the emanation, as in such cases a small percentage of ThX was usually found with the active deposit. This precaution also precluded the possibility of any appreciable quantity of active deposit from radium, which is always present in mesothorium, being attracted to the plates. In addition, an interval of at least five hours was allowed to elapse-after removal from the emanation-before any measurements of activity were made. The period of decay was then governed by that of ThB (10.6 hours). Small pieces of quartz were used in some experiments instead of platinum, but no difference was observed in the temperatures of volatilisation. This result is different from that obtained by Makowert in the case of radium active deposit. In every experiment measurements of the activity of the foil were made for some time before it was placed in the furnace, an $\alpha$ or $\beta$-ray electroscope being used for the purpose.

\section{(i.) Measurements by a-rays.}

The deposit was heated to the required temperature, in most cases for 15 minutes, as the volatilisation appeared to be to some extent a time effect, and immediately after removal from the furnace the activity was again measured, and continued for several hours, until the decay was exponential, with the period of ThB.

Fig. 1 illustrates graphically the results of one of these experiments. The first part (A) gives the curve of activity before the plate was heated, the period of decay then being that of $B$. The active plate was in the furnace for a time indicated by $a-b$. After removal from the furnace, the curve of activity was much steeper, as is shown in the latter portion (B) of the curve. In order to calculate the percentage of Cactivity removed by heating, the curve $B$ was produced back to the point $\mathbf{Q}$ on the line $\mathbf{P} c$, which corresponds to the time when the plate has been in the furnace four minutes. Previous observations had indicated that in this time, at a given constant temperature, practically the maximum amount of active matter has been volatilised. The percentage of $\mathrm{C}$ removed is then

* Miss Slater, loc. cit.

$\uparrow$ Makower, "Le Radium," 6, p. 50, 1909. 
given by $100 \mathrm{PQ} / \mathrm{Pc}$. To calculate the percentage of $\mathrm{B}$ removed, readings were taken six or seven hours after the foil was heated. The values then observed were corrected (to the. time of heating) for decay of $B$ (period 10.6 hours), and the percentage reckoned as in the case of $C$.

Fig. 2 embodies the results of a great number of experiments of a similar kind at various temperatures, the measurements.

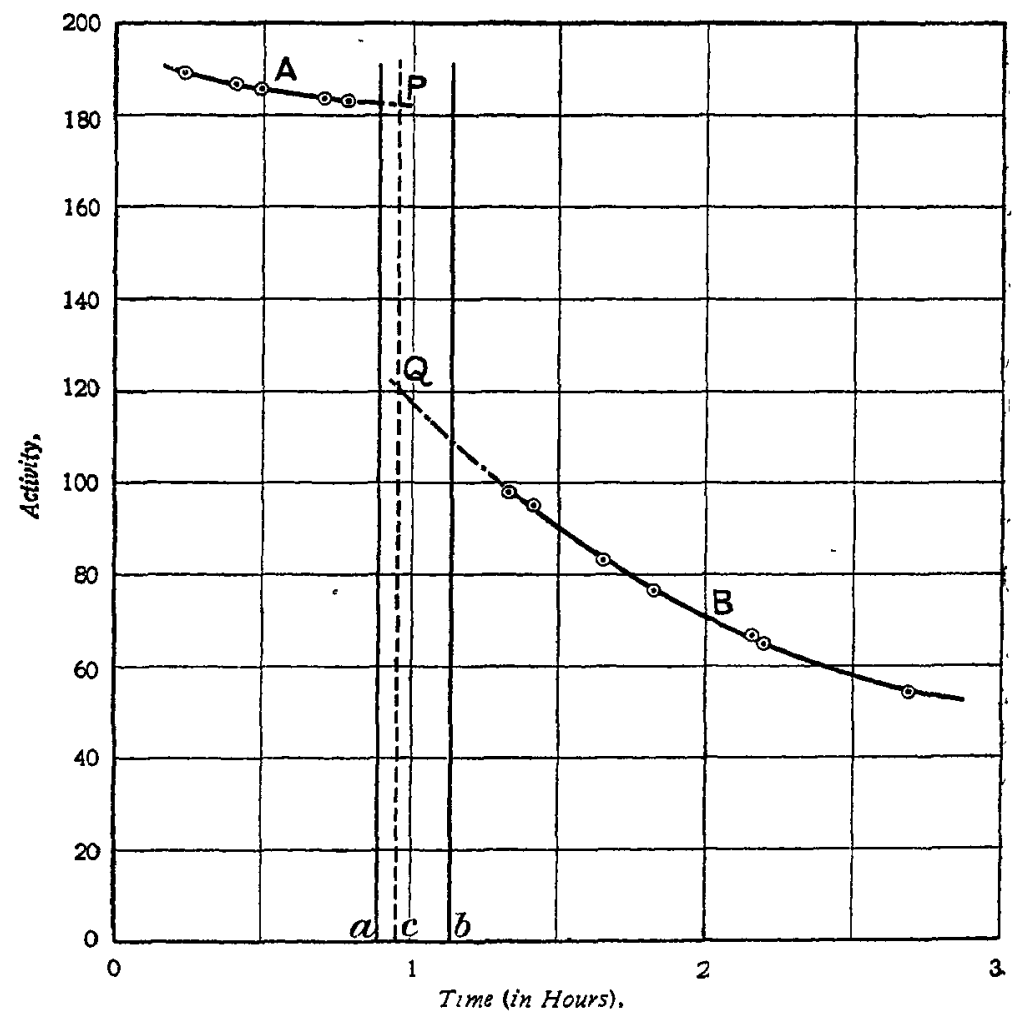

FIG. 1.

all being of the $\alpha$-radiation. It can easily be deduced from the curves that:-

1. Both $\mathrm{B}$ and $\mathrm{C}$ begin to volatilise at about $750^{\circ} \mathrm{C}$. :-B. perhaps at a temperature slightly lower than $\mathrm{C}$.

2. Between $750^{\circ} \mathrm{C}$. and $1,200^{\circ} \mathrm{C}$. a greater percentage of $\mathrm{B}$ than of $\mathrm{C}$ is volatilised at any given temperature.

3. Volatilisation of both $B$ and $C$ is practically_complete at $1,200^{\circ} \mathrm{C}$. 
4. There is an inflexion of the $\mathrm{C}$ curve between $750^{\circ} \mathrm{C}$. and $900^{\circ} \mathrm{C}$; in fact the curve is similar to two of the " B " curves placed end to end. This points to the possibility that between $750^{\circ} \mathrm{C}$. and $900^{\circ} \mathrm{C}$. only one $\alpha$-ray product is being volatilised ; after $900^{\circ} \mathrm{C}$. the curve becomes very much steeper, as if the second product is also being driven off.

5 . The inflexion occurs at a point where about 35 per cent. of the $\alpha$-ray activity has disappeared.

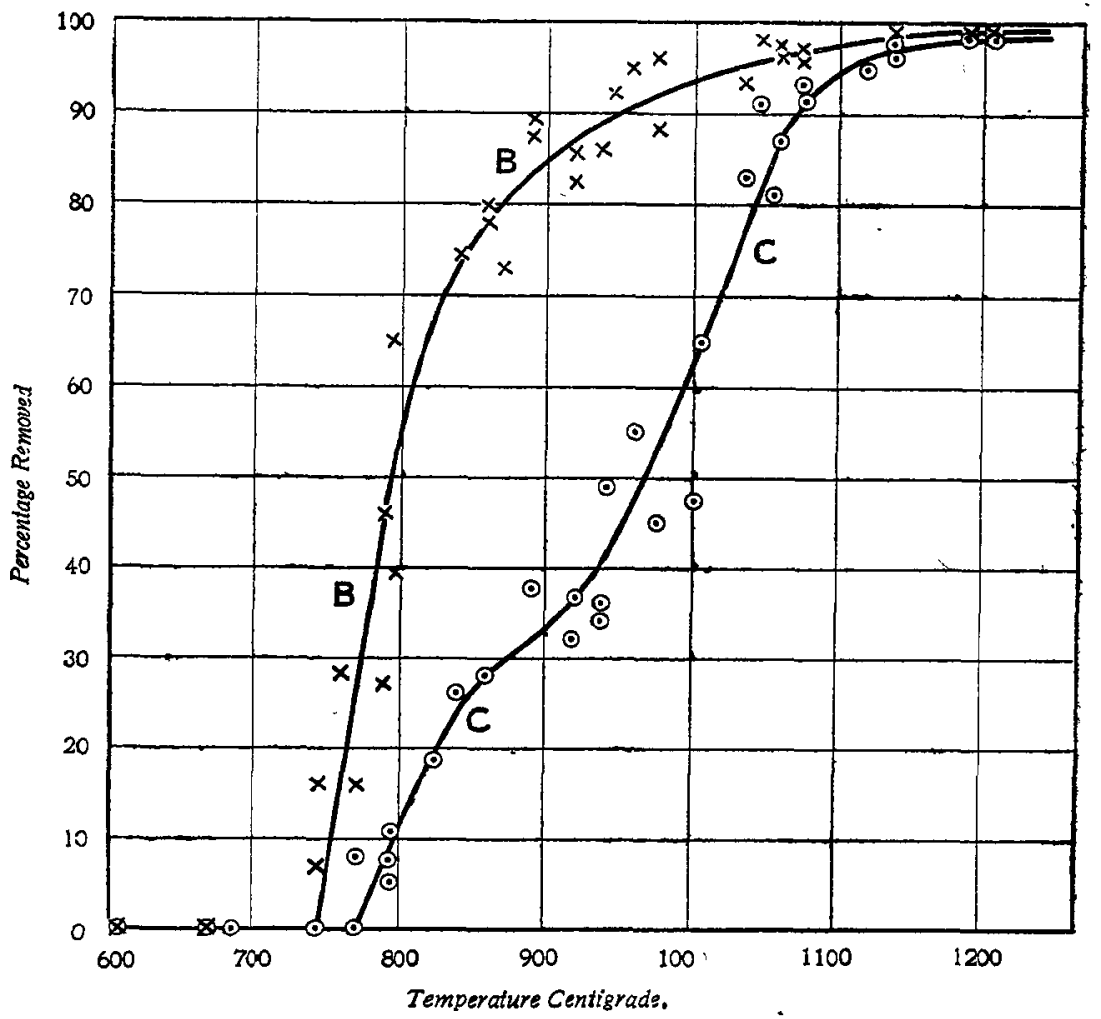

FIg. 2.

(ii.) Measurements by $\beta$-rays.

In view of the fact, before mentioned, that the ratio of $\mathrm{C}_{a}$ to $\mathrm{C}_{2}$ is as $35: 65$, $t$ was recognised that the shape of the $\mathrm{C}$ curve was significant. In order to throw more light on the question similar experiments were conducted, employing this time the 
$\beta$-radiation. The result of one of these experiments is exhibited in Fig. 3. It is noticeable that :-

1. There is at first a steep rise of the curve, undoubtedly due to the growth of $\mathbf{D}$, which is known to be at any rate more vclatile than $\mathrm{B}$ or $\mathrm{C}$ * $^{*}$

2. The curve then descends with a period a little greater than that of $\mathrm{C}$.

3. The activity after several hours decays with the period of $B$. As the result of many similar experiments at various temperatures it was found that, as measured by $\beta$-rays, $\mathrm{C}$ does not begin to volatilise till a temperature of about $900^{\circ} \mathrm{C}$. is reached. It

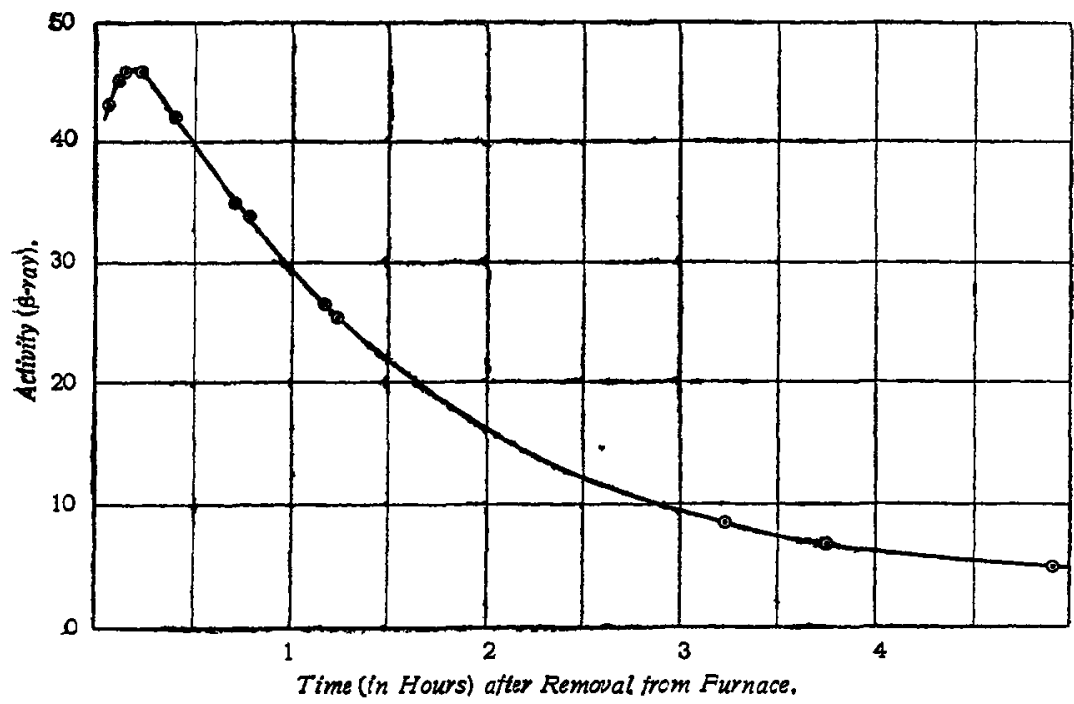

Fia. 3.

is significant that this temperature, again, is that at which the second part of the $\mathrm{C}$ curve, as obtained by $a$-ray measurements, commences. An explanation of these observations will be attempted in section IV.

(b) Experiments with the Active Deposit Dissolved in Acid.

As some of the researches quoted $\dagger$ were carried out with the active deposit dissolved in acid, some experiments were done with solutions of the active substance in pure conc. $\mathrm{HCl}$, or

* v. Lerch and v. Wartburg, "Wien. Ber.," 118, p. 1575, 1909.

† Marsden and Wilson, Miss Meitner, loc. cit. 
$\mathrm{HNO}_{3}$. As a result it was found that in the case of the $\mathrm{HNO}_{3}$ solution volatilisation occurred at practically the same temperatures as before. With $\mathrm{HCl}$, however, the activity disappeared at a much lower temperature, commencing, in fact, at about $300^{\circ} \mathrm{C}$. In the case of solution in $\mathrm{HNO}_{3}$, as with the undissolved product, the deposit is probably in the form of an oxide, while the solution in $\mathrm{HCl}$ is no doubt a chloride. In this connection some results of Dr. Schrader's* are interesting. He found that with the active deposit of actinium, volatilisation occurred at a much lower temperature if a platinum wire coated with it were first exposed to an atmosphere of chlorine. Russell $\dagger$ also discovered that in hydrogen $\mathrm{RaC}$ was volatile at $360^{\circ} \mathrm{C}$., while in oxygen the temperature had to be much higher. In Marsden and Wilson's Paper, again, it is shown that ThC volatilises at about $300^{\circ} \mathrm{C}$. when dissolved in $\mathrm{HCl}$.

\section{(c) Volatility of Thorium $D$.}

As the result of experiments similar to that exhibited graphically in Fig. 3 ( $\beta$ curve), it was concluded that D begins to volatilise at about $500^{\circ} \mathrm{C}$. The active deposit, on a platinum foil, and undissolved in acid, was heated for 15 minutes in the furnace at various temperatures. $\mathrm{Up}$ to $500^{\circ} \mathrm{C}$. there was no break at all in the curve of activity as obtained by $\beta$-ray measurements. At this temperature, however, some of the $D$ was removed (as was indicated by the initial rise of the curve after removal from the furnace). The same phenomenon was observed at higher temperatures, up to about $900^{\circ} \mathrm{C}$. Beyond this temperature, however, provided the active plate was in the furnace long enough (e.g., 10 or 15 minutes) there was no perceptible rise of $\beta$ activity due to growth of $D$. Assuming that $\mathrm{C}_{a}$ is removed almost entirely at $900^{\circ} \mathrm{C}$., while $\mathrm{C}_{\beta}$ is not removed to any extent, this verifies the experiments of Marsden and Darwin, $t$ and of one of us, $\$$ that $D$ arises entirely from the 35 per cent. branch,viz., $\mathrm{C}_{\alpha}$.

\section{IV.-Discussion of the Results.}

The fact that volatilisation of both $\mathrm{B}$ and $\mathrm{C}$ commences at $750^{\circ} \mathrm{C}$, and is not complete until about $1,200^{\circ} \mathrm{C}$., precludes the possibility of an absolute separation of these two products

* Schrader, " Phil. Mag.," 24, p. 125, 1912.

+ Russell, " Phil. Mag.," 24, p. 134, 1912.

\pm Marsden and Darwin, loc. cet.

\$ A. B. Wood," "Phil. Mag.," pp. 586-597, Oct., 1913. 
from each other by this method. This wide range of temperature seems rather remarkable. It may be that the oxides are gradually reduced to the pure metal, which is not volatilisable except at a very high temperature. The case may be, in fact, similar to that of mercury, which, when heated in air, oxidises at a comparatively low temperature, and is again reduced to pure mercury at a considerably higher one. A temperature greater still is then required to vaporise the metal.

In order to explain the results already quoted in the present Paper it is evident that some modifications must be made in schemes of disintegration that have been proposed up to now. The following arrangement appears to us to fit the facts better than any other we can devise :-

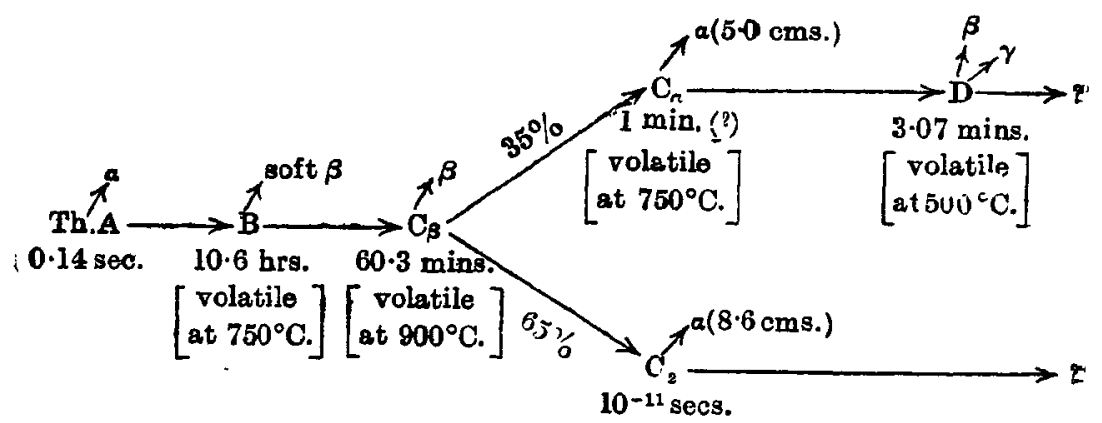

It will be observed that $\mathrm{C}_{\beta}$ is assumed to be a separate product, which breaks up in two ways, 35 per cent. of the disintegration producing $\mathrm{C}_{\alpha}$ and 65 per cent. giving $\mathrm{C}_{2}$. As in the case of $\mathrm{B}$ and $\mathrm{C}$ (the latter taken as a whole), there is only a partial separation of the two products, but evidently $\mathrm{C}_{a}$ is more readily volatile than $\mathrm{C}_{\beta}$.

The scheme accounts for:-

1. The branching of $\mathrm{C}_{\alpha}$ and $\mathrm{C}_{2}$.

2. The differences in volatility obtained in $\alpha$ and $\beta$-ray measurements respectively. Neglecting the small percentage of $\beta$-radiation from $\mathrm{D}$, which can easily be identified and allowed for, all the $\beta$-activity measured in the present experiments comes from $\mathrm{C}_{\beta}$, as the base of the electroscope employed was too thick to be penetrated by the soft $\beta$-rays from $\mathrm{B}$. The experiments show then that $\mathrm{C}_{\beta}$ is not removed to any perceptible extent until a temperature of $900^{\circ} \mathrm{C}$. is reached, while $\mathrm{C}_{\alpha}$ begins to volatilise at $750^{\circ} \mathrm{C}$.

3. The periods of $\mathrm{B}$ and $\mathrm{C}(\mathbf{1 0} .6$ hours and 60.3 minutes. 
respectively). On the above scheme the period of $C$ isgoverned by that of $\mathrm{C}_{\beta}$. This assumes, of course, that the period of $\mathrm{C}_{\alpha}$ is comparatively small (perhaps only a minute or so). This will be discussed later.

4. The inflexion in the curve of volatilisation of $C$. This has been already mentioned. (See Section III.)

5. The constant ratio of the activities of $\mathrm{C}_{\alpha}$ and $\mathrm{C}_{2}$. Several experiments were tried in the present research in order to test the constancy of this ratio. Measurements were taken of the activity of the plates before and after heating :-

(a) With active plate uncovered;

(b) With plate covered with just sufficient aluminium foil to. stop the $\alpha$-rays of range $4.8 \mathrm{~cm}$.

The ratio of activities (before and after heating) was about the same in both cases $(a)$ and $(b)$. This result, however, is easily explained if we make the assumption suggested in (3) above, i.e., that the period of $\mathrm{C}_{\alpha}$ is no more than a minute or so. It must be remembered that by far the greater proportion of the $\alpha$-activity is produced by $\mathrm{C}_{2}$ in virtue of-

(a) Its longer range $(8.6 \mathrm{~cm}$. to $4.8 \mathrm{~cm}$.).

(b) The fact that it gives twice as many $\alpha$-particles.

(c) It produces its effect in both cases, whether the foil is covered or uncovered.

It would therefore be difficult to prove the existence or otherwise of a small amount of $\mathrm{C}_{a}$. In any case, assuming that $\mathrm{C}_{\alpha}$ has a short period, the above scheme shows that $\mathrm{C}_{a}$ and $\mathrm{C}_{2}$ would each be in equilibrium (in the ratio of 35 to 65 ) with the common parent product $\mathrm{C}_{\beta}$ in a very short time-almost, in fact, before any reliable measurements of the relative $\alpha$ activities could be made.

As a great deal in the explanation given depends on the life of $\mathrm{C}_{\alpha}$ being considerably shorter than that usually attributed. to $\mathrm{C}$ as a whole (viz., 60.3 minutes), it is of importance to note that, in order to fit the relation given by Geiger and Nuttall,* the period of $\mathrm{C}_{a}$ (with its range $4.8 \mathrm{~cm}$.) should be only two or three minutes. The range usually attributed to $\mathrm{C}_{\alpha}(4.8 \mathrm{~cm}$.), was determined by Marsden and Barratt $\dagger$ by a scintillation method, which is well known to give lower results than the usual ionisation determinations. $\ddagger$

* Geiger and Nuttall, "Phil. Mag.," 22, p. 613, 1911 ; 23, p. 439, 1912.

† Marsden and Barratt, loc. cit. ; Barratt, "Proc." Phys. Soc., 24, p. 112 1912.

¥ Rutherford, "Radioactive Substances and their Radiations," p 161, 1913. 
If the range were taken as $5.0 \mathrm{~cm}$. (as given by some experimenters),* then Geiger and Nuttall's relation would assign a half-period of less than a minute to $\mathrm{C}_{\alpha}$.

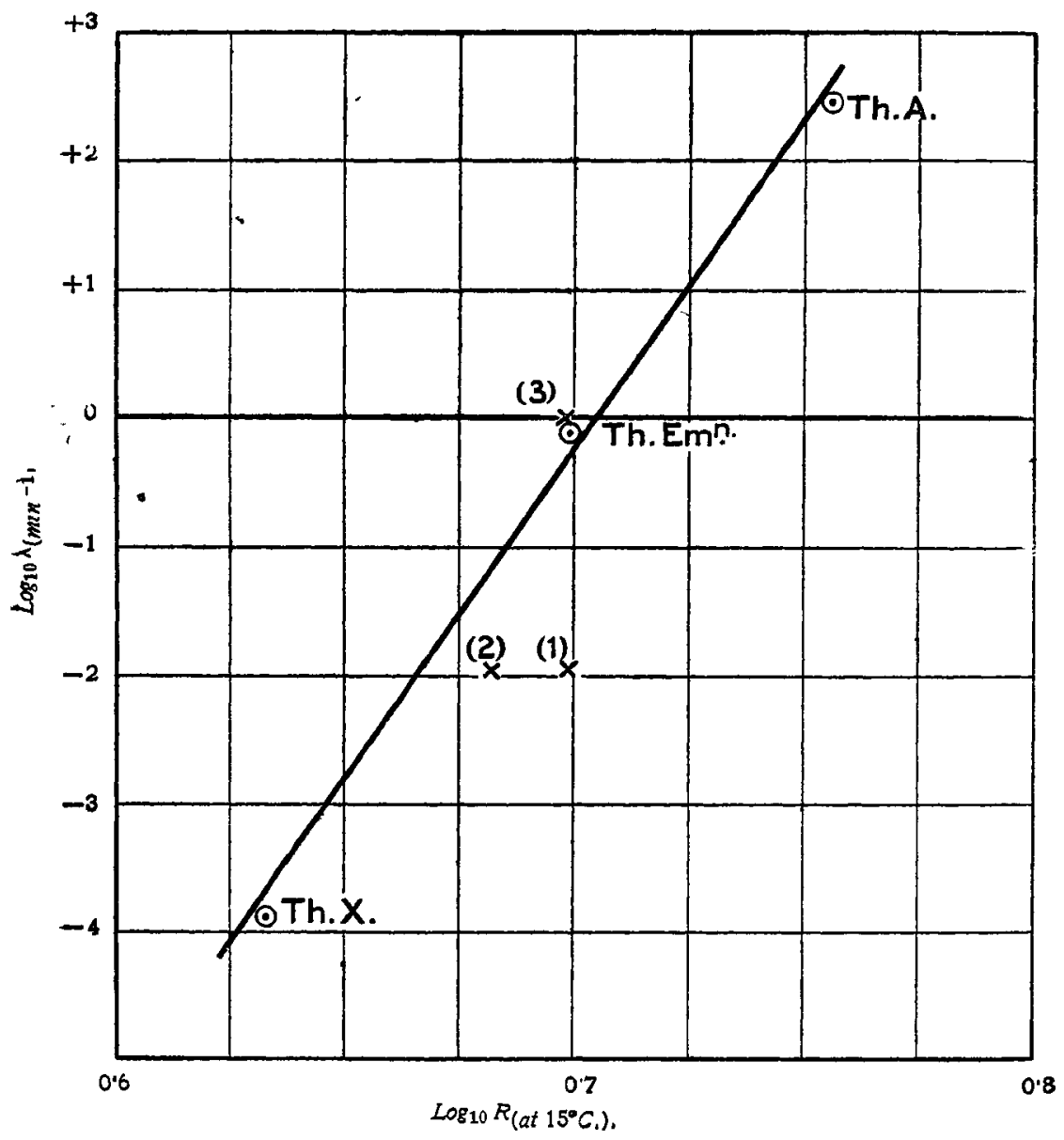

Fic. 4,

This is clearly shown in Fig. 4, the crosses indicating the positions that would be occupied by $\mathrm{C}_{\alpha}$ if its half-period and range were respectively-

1. 60.3 mins.; $5.0 \mathrm{~cm}$.

2. 60.3 mins.; $4.8 \mathrm{~cm}$.

3. 40 secs. ; $5.0 \mathrm{~cm}$.

*Hahn, "Phys. Zeit.," 7, p. 456, 1906. 
Experiments are in progress with the object of further elucidating the points raised above. The radium and actinium series are also being tested in a similar way; and by heating these products in atmospheres of different gases it is hoped that further knowledge may be gained of the separability, \&c., of the members of these series.

\section{Summary.}

1. By heating thorium active deposit to various temperatures: up to $1,250^{\circ} \mathrm{C}$., it is found that $\mathrm{B}$ and $\mathrm{C}$ each begin to volatilise at $750^{\circ} \mathrm{C}$. (when measured by $\alpha$-radiation), but volatilisation is not complete until a temperature of about $1,200^{\circ} \mathrm{C}$. is reached.

2. The curve of activity of $\mathrm{C}$ is similar to two "B-curves" in series, the inflexion occurring at about $900^{\circ} \mathrm{C}$., where about 35 per cent. of the $\alpha$-activity has been removed.

3 . When measured by its $\beta$-activity, $\mathrm{C}$ volatilises at $900^{\circ} \mathrm{C}$. and $\mathrm{D}$ at $500^{\circ} \mathrm{C}$.

4. In explanation of these results, it is assumed that $\mathrm{C}_{\beta}$ is a separate product, which breaks up in two ways, each with the expulsion of an $\alpha$-particle, producing $\mathrm{C}_{\alpha}$ and $\mathrm{C}_{2}$ as shown in the following scheme:-

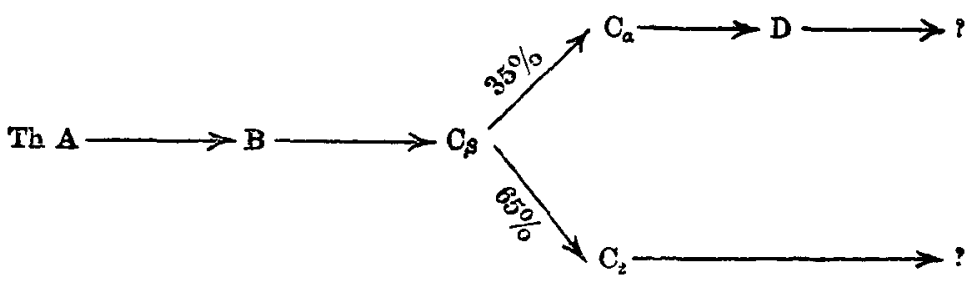

5. Temperature of volatilisation " in $\mathrm{HNO}_{3}$ " same as ordinary active deposit. Temperature of volatilisation in $\mathrm{HCl}$, $300^{\circ} \mathrm{C}$. for Th.B and C.

The experiments have been carried out at the Woolwich Polytechnic, and our best thanks are accorded to the Principal and Governors of that institution; also to Mr. F. H. Glew, who very kindly lent us, for a considerable period, the mesothorium used in the research.

\section{ABSTRACT.}

On heating thorium active deposit to various accurately measured temperatures up to about $1,250^{\circ} \mathrm{C}$., it is found that $\mathrm{B}$ and $\mathrm{C}$ each com. mence to volatilise at $750^{\circ} \mathrm{C}$, , but the volatilisation is not complete until $1,200^{\circ} \mathrm{C}$. is reached, the measurements being made by an a-ray electroscope. The $\mathrm{C}$ curve is peculiar, being similar to two of the 
B curves placed end to end, the inflexion occurring between $750^{\circ} \mathrm{C}$. and $900^{\circ} \mathrm{C}$., where about 35 per cent. of the $a$-activity has been removed. When measured by $\beta$-radiation, $C$ is not volatile until a temperature of $900^{\circ} \mathrm{C}$. is reached. $\mathrm{D}$ commences to volatilise at $500^{\circ} \mathrm{C}$.

To explain these results, it is assumed that the part of $\mathrm{C}$ which produces the $\beta$-rays-riz., $\mathrm{C}_{\beta}$-is a separate product, which is not so readily volatile as $\mathrm{C}_{\alpha}$. A suitable scheme of disintegration is suggested.

\section{DISCUSSION.}

Dr. R. S. WILLows congratulated the authors on their able treatment of the subject. The suggested scheme met most of the requirements of the case and was not in contradiction with any of the other known properties of the thorium series. He hoped the authors would extend their work to other radio-active series.

Dr. S. RUSS drew attention to the apparent lack of parallelism between the characteristics of the thorium and radium series. The volatility of thorium $B$ appeared to be not very different from that of thorium $C$, whereas in the radium series, radium $B$ is the most, and radium $C$ the least, volatile of the series. Again, the authors concluded that there was no appreciable difference in the volatility of the thorium active deposit from a quartz or a platinum surface, whereas there was an appreciable difference in the case of the radium active deposit as Dr. Makower had shown.

Mr. D. OWEN observed that one of the products was stated to have a period of $10^{-11}$ second. He thought it hardly possible to catch a product which only lived for that time.

Mr. BARRATT said that only two surfaces were used, quartz and platinum, on account of the high temperatures to which they had to be sub. jected. In these cases there had certainly been no difference. When different acids were used, considerable differences were observed in the temperature of volatilisation. The period, $10^{-11}$ second, assigned to $\mathrm{Th} \mathrm{C}_{2}$ was simply in order to fit the Geiger-Nuttall relation. The curve connecting $\log (V)$ and $\log$ (Range) is a straight line, and the period $10^{-11}$ second was necessary to make the product fit the curve. 